\title{
Artificial intelligence, transhumanism and translation as a universal property of thinking
}

\author{
Miroslava Metleaeva (Luchianchicova)
}

Miroslava Metleaeva (Luchianchicova) - Doctor of Philology, Researcher Institute of Romanian Philology "Bogdan Petriceicu-Hasdeu", Republic of Moldova

\begin{abstract}
Transhumanism assumes human improvement as an unfinished link in evolution based on its fusion with technological elements. The new human-machine organism, from the author's point of view, is a dubious boon for human civilization and the planetary ecological system. This idea is, first of all, anachronistic and pursues the main goal - the singularity, i.e. control over human intellectual energy by technology. Cognitive activity and one of its most difficult aspects - translation of thought into linguistic form - represent an obstacle to the creation of perfect Artificial Intelligence, since translation is not limited to formulas. The accuracy of terminology and the absence of ambiguity of the word are the basis of Artificial Intelligence and, at the same time, the limitation of the development of linguistic thinking. The article outlines the sequence of the translation process, the difference between the mental operations of Artificial Intelligence and humans. The author assumes that translation is a universal property of human thinking, and the process of translating thought into speech form is due to bio-genetic, emotional, socio-historical memory and experience, since a person translates his thought from a fuzzy, vague thought-text into a linguistic form.
\end{abstract}

\section{KEYWORDS:}

Transhumanism, man-machine, singularity, Artificial Intelligence, translation process, memory, experience.

\section{INTRODUCTION}

Transhumanism is an evolving trend in philosophy that has become increasingly important in understanding the phenomena of the main aspects of social life taking into consideration the future. It would seem that the main goals of transhumanism - the constant improvement of man as an unfinished link of evolution on the basis of scientific and technical discoveries and new technologies that can bring a person to a new, previously unattainable level, have good 
ryor

intentions. However, while at the end of the 20th century this direction was perceived by futurologists positively as a whole, over time the assessment of the ideas of transhumanism began to become clearly ambiguous. Opponents of this line of philosophical thought have come to the conclusion that the realization of ideas of transhumanism will undermine the traditional values of humanism in all spheres of human existence, developed by millennia of human history.

Mark O'Connell, author of the book "To be a machine: Adventures among cyborgs, utopians, hackers, and the futurists solving the modest problem of death" demonstrates that in spite of all its aspiration for the future, transhumanism has the paradoxical power of its anachronism. In the future, where transhumanism is eagerly striving, it will always still look back into the past" (1).

Without delving into the origins of the emergence of transhumanist ideas in their modern understanding, one should nevertheless turn to the teachings of Ludwig Feuerbach with his thesis that man created God in his own image and likeness.

Feuerbach clearly traces the ideas of collective consciousness and the conclusion that the human community can never achieve perfection and happiness, provided there are individuals in it (2, p. 82).

Kai-Fu Lee, a renowned Chinese scientist in the field of modern technology, emphasizes that one can be optimistic in the development of Artificial Intelligence only by remembering the responsibility in this area. As an example of the technocratic direction of transhumanism, he cites the ideas of Ray Kurzweil, the inventor and the largest ideologue of GOOGLE, who believes that in the future, people and machines will merge together. "According to him, people will... constantly renew body tissues with the help of nanorobots injected into the bloodstream. Kurzweil predicts that by 2029 we will get computers with intelligence comparable to human, and the singularity point will be reached by $2045 "$ (3, p. 144).

Singularity as a term means the superiority of machine intelligence over the human person who created it. However, with all the cybernetic improvements of the intellectual creature with the inclusion of a truncated biostructure (mainly brain structures), its modifiers - the technocratic elite - pursue the main goal - managing intellectual energy within the strict framework of the technology.

That is, the question of power is again raised: there is a return to the old ideas of the creation of human, starting with the creation of Adam, continuing with the Golem, and then with Frankenstein (we will not mention all the automata imitating a person, which the great Leonardo da Vinci did) right down to the ideas the theoretical founder of transhumanism Ludwig Feuerbach and the earlier Thomas Hobbes. Hobbes argued that order in society can be achieved only through the conclusion of an agreement between citizens and the state, to which each citizen cedes his power, receiving in return the protection of life and property (1, p. 132).

The question is what is the relation of translation, as one of the types of human activity, to pressing philosophical problems, including transhumanism?

European organization COST - European Cooperation in Science \& Technologies has developed a project with three strategic priorities: the promotion and dissemination of best practices, the development of interdisciplinary research for breakthroughs in 
science and the empowerment of attracting young researchers and innovators. COST fulfills its mission by funding upstream, excellence-oriented, open and inclusive networks for peaceful purposes in all areas of science and technology.

In a document which was sent to the Institute of Romanian Philology "Bogdan PetriceicuHasdeu" by the Ministry of Education, Culture and Research of the Republic of Moldova in order to attract employees who want to join the participants of the COST project in the direction chosen by the applicant, I was interested in the direction CA19102 Language in the Human-Machine Era (pag.4): "Within the next 10 years, many millions of people will be ... wearing relatively unobtrusive ... devices that offer an immersive and high-resolution view of a visually augmented world". This is the 'human-machine era', a time when our senses are not just supplemented by handheld mobile devices, but thoroughly augmented. The language we see, hear and produce will be mediated in real time by technology. This has major implications for language use, and ultimately language itself. Are linguists ready for this? Can our theory, methods, and epistemology handle it?" (4).

To some extent, the project developers identified the ethical consequences of the emergence of the language of technology: inequality of access to technology, confidentiality and security problems, new vectors for deception and crime, etc.

We list the areas of expertise in the scientific field related to the topic of our article languages and literature: translation and interpretation; tongue; Artificial Intelligence; human machine; interfaces, etc. COST project prioritizes languages and literature, translation and interpretation.
Translation, with all its antiquity and with all its significance in most spheres of human activity, continues to remain terra incognita in many of its aspects. The post-war information boom which led to significant changes in translation activities, as well as an interdisciplinary approach to the problems of linguistics, raised the issues of extralinguistic aspects of verbal communication, made possible the further development of the science of translation. Humboldt's theory of the impossibility of an adequate translation reflected the philosophical idea of the unattainability of perfection. It received a tangible blow, since linguistic factors give rise not only to difficulties for translation, but also conditions for overcoming them: "Regardless of the validity of one or another hypothesis, the presence of essential universal features in all languages is beyond doubt. This universality, of course, is an important prerequisite for a successful transition from one language to another in the process of translation " $(5$, p.17).

\section{OBJECTIVES}

Translation, like an X-ray, reveals the words hidden behind the clothes. From our point of view, what is being translated, namely, the author's literary text, is a separate stable mega-unit, i.e. a huge unchangeable combination of words united by the author's idea. The author's literary text, is a stable semantic mega-combination of words. With all the achievements of modern translation in the field of professional and technical translation, there are still gaps in the theory of literary translation. The fact that only "input" and "output" data are available to real observation and scientific analysis, and the intellectual process of translation transformation itself occurs secretly, in the most complex psycholinguistic energy nodes of the translator's brain activity, turns the theory of translation into a comparative 
r.m\%\%

discipline. All conclusions about the translation mechanism are made on the basis of a comparison of the initial and effective data. The data for comparison are works - the original (author's) and final (translation result).

Schematically, the explicit sequence of the translation process is a double logical semantic chain, where the external level is an emotional manifestation $\rightarrow$ determining the originality of the source text $\rightarrow$ establishing a key lexical sign; and the internal (psychophysical) level is pondering / spiritual attitude $\rightarrow$ the cognitive system $\rightarrow$ conflict at the intercultural level $\rightarrow$ establishing the interaction of the author/ translator. These two sides of the process are combined in the inter - and extra steps of compiling a comment, the result of which is the selection and reproduction of an adequate idiolectic key sign.

We have before us two sources of knowledge: objects of the external world and the activity of our own mind. External feelings are sent to the first, as a result of which impressions (ideas) about external things are obtained. As for the second source of knowledge, and it includes thinking, doubt, faith, reasoning, cognition and desires, it is known by a special inner feeling - reflection. Thus, a mental reaction can occur on two levels: a) perception, thought, desire; b) observation, contemplation of these ideas, thoughts and desires (6, p.257).

\section{MATERIAL AND METHODS}

In my research on the interpretation of translations of the world literature masterpiece of the poem "Luceafer" by the Romanian poet Mihai Eminescu into Russian, I place an emphasis on the introspective study of my own thought processes that occurred during the translation activity. For all its subjectivity, the "introspection method" is considered one of the basic methods of language research. Linguistic intuition is characteristic to one degree or another of all users of the language. These abilities are examples of the manifestation of selfobservation, which allows a person to be directly aware of certain aspects of the language. However, we do not absolutize this method, but use it in combination with others, using different approaches to the problems of translating poetry in our work. Reflections of writers and translators about the process of converting thought into linguistic form coincide with our observations.

\section{DISCUSSIONS}

When translating, our main goal was to semantically convey the author's idea with maximum fidelity to the artistic features of the original. The whole difficulty was that we had a linear text in front of us, and we had to convey the bulk of the idea to the target language without departing from the text. There was a risk awaiting each translator to become a "slave" to the visible, linear part of the content.

When translating, our main goal was to semantically convey the author's idea with maximum fidelity to the artistic features of the original. The whole difficulty was that we had a linear text in front of us, and we had to convey the bulk of the idea to the target language without departing from the text. There was a risk awaiting each translator to become a slave the visible, linear part of the content.

The transfer of the volume of an idea depends on the volumetric understanding by the translator of its meaning and its ability to identify nicks that are the key to opening doors to non-textual (subtext, intertext, intratext, etc.) associative space. 
All these elements of creative manifestations are an integral part of the mental activity of the translator of fiction (I emphasize, fiction), inextricably linked with the imagination. This mental activity is a field of collision of critical thinking, directed both at other people's judgments and at the translator's own judgments. This field of creative thinking is associated with generating your own ideas and evaluating the ideas of the author of the original text.

In psycholinguistics, there is the concept of a precedent text, that is, a text that is known to culture and to which there are references in speech. A reference may not be transformed and transformed, up to a single component - a word, increasing the semantic load of the text, and activates the reader (in our case, the translator).

There is not a single writer in any of the epochs who began to engage in creativity from scratch: consciously or subconsciously, he has concentrated sufficient national and world literary experience, which M. M. Bakhtin called the "memory of literature". In a broader sense, this memory can be identified with the previous experience.

Bogdan Giu, commenting translation activities, concludes: "We do not do it in different ways and, to a different degree, do nothing but translate, we initially translate. We do what changes everything. Or, more precisely: it can change everything ..." ( 7 , p.2).

He brings us to a very important conclusion: the authors are the first translators and that translation begins much earlier than interlinguistic translation itself, when an attempt is made to recreate the text of one language within the framework of another, that is, an attempt to transfer it from one linguistic space into the bizarre structures of another language.

If we approach the problem of translation more broadly, then we come to the conclusion that translation is a universal property of human thinking. Before we put thought into speech form, a process takes place in the mind, the sequence of which, in our opinion, is as follows: amorphous thought-form> thought-idea> thought-text> translation (transmission) into the source language for communicative exchange.

At this stage, we can talk about decodification, interpretation, translation of the "language" of the author's thinking by the author himself to reproduce what he wants to convey to the receptor (reader). Reflections on the creative act of transforming the way of thinking into verbal reflection, i.e., on translating inspiration into linguistic parameters, is an object of interest not only to psychology and philosophy, but also to the creators of literary texts themselves. This was very clearly expressed in his poem "Silentium" by the Russian poet F. Tyutchev "The thought uttered is a lie".

V.D. Psurtsev dwells on the aspect of sense formation (both in generation and in perception), noting that "the specificity of a literary text (...) lies in the fundamental absence of its creator and its interpreter of the installation of" simple evidence ", the onedimensionality of meaning. (Therefore, the antipode of the literary text will be a text that does not have such an attitude)" (8, p. 251252).

In this regard, the role of figurativeassociative components becomes an additional criterion. It is figuratively associative components that stylistically mark the literary text. It should also be noted a very 


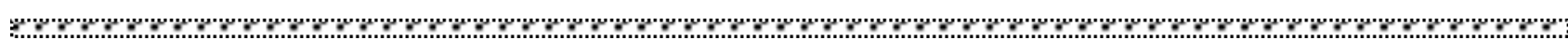

significant remark by V.D. Psurtsev, which is directly related to the translation: “(...) the text of the original and the text of the translation (...) are linear in their presence, while the concept and meaning are voluminous" $(8, \mathrm{p}$. 255)

Artificial Intelligence is not able to cope with the tasks that the author faces when transforming his own thought-text from an amorphous thought-form into his native language. Likewise, no machine can cope with the tasks of translating a literary source text into a target language. The transmission of the author's volumetric thought is associated with the codes of both the source and target languages. This decoding depends on the thinking of the translator and all psychosocial and other components of the environment of both participants in the translation process.

"Social influence is ubiquitous. It is carried out everywhere and always. This is a part of the structure of the world "( 9, p.15). One of the founders of social psychology, Kurt Lewin, gave us a long time ago a simple equation: "behavior is a function of two variables - the unique personality of the individual and the situation in which he or she acts." (9, p.51).

It is impossible for both the writer and the translator to distance themselves from this, despite the recognition of their individuality in the sphere of influence, are still under the influence of a second, no less significant component of influence - the power of the situation, the power of the temporal environment.

In the philosophy of postmodernism, the phenomenon of the power of language is widely analyzed. According to the concept of R. Bart, theoretically only two alternative variants of the correlation of power and language are possible: the cooperation of language with the government and its opposition to it - linguistic neutrality with respect to power, according to $\mathrm{R}$. Bart, is in principle impossible, "some languages speak out, develop, get their characteristic features in the light (or under the shelter) of the Authority ... Other languages are developed, acquired, armed outside the Authority and / or against it "(10). In the terminology of R. Barth, the languages of the first type are designated as "enkratic languages" (which correspond to "enkratic types of discourse"), the languages of the second type are referred to as "acratic" (and, respectively, "acratic types of discourse") (11).

Translation and interpretation are inseparable, and the influence of external factors on translation activity is widespread, as evidenced by numerous examples of inadequate translations created under the pressure of socio-historical factors of a particular era.

In this regard, Skopos theory, put forward in 1984 by German scientists Katharina Rice (K. Reiss) and Hans Vermeer (H. Vermeer) in the work "Grundlegungeiner allgemeinen Translationstheorie" (12), gained quite wide popularity. The authors proceed from the fact that the parameters of the translation are determined by the needs and requests of the reader-customer, that is, the purpose of the translation is the intended recipient, and the translator is free to either reproduce the original, or deviate from it, or completely neglect it, not particularly paying attention to linguistic subtleties. In fact, this theory claims to be the scientific justification for targeted translation.

From our point of view, this is one of the steps to mastering the thought process if it is 
impossible to reproduce it in full in an artificial version of the brain-machine. That is, if it is impossible to control thought processes from the inside, then it is much easier to influence them from the outside.

R. Bart noted: "Incidentally, the encratic language (that which arises and spreads under the protection of power) is by its very nature a language of repetition; all official linguistic institutions are machines that constantly chew the same gum: school, sports, advertising, mass culture, song production, media nonstop reproduce the same structure, the same meaning, and sometimes the same the same words: a stereotype is a political phenomenon, it is the very embodiment of ideology " (Quoted from the Russian translation by G.K. Kosikov, 13, p.494).

Thinking stereotypes narrow the horizons of consciousness, imposing automatic algorithms, and suppress individual thinking. When translating a text into a target language for Skopos theory, the degree of its correspondence to the original is insignificant if it meets a specific goal. Before us is not a theory of translation, but a theory of text alteration, a theory of its commercialization on the world market.

These ideas have long been reflected in the works of world literature. A harsh formulation of this phenomenon, inherent in the coming "society of technological ideas", which destroyed the absurdity of the "consumer society" and leads to a complete absence of freedom, was formulated in 1948 by George Orwell in his prophetic anti-utopia "1984":

"The purpose of Newspeak was not only to provide a medium of expression for the world-view and mental habits proper to the devotees of Ingsoc, but to make all other modes of thought impossible... Newspeak was designed not to extend but to DIMINISH the range of thought, and this purpose was indirectly assisted by cutting the choice of words down to a minimum" (14, p.376-377). And then follows: "Pre-revolutionary literature could only be subjected to ideological translation - that is, alteration in sense as well as language (14, p.391)

In the coming Oceania, the emotional and cognitive side of life is reduced to a minimum: books are written on machines, knowledge of foreign languages is prohibited for the majority. Here the doctrine of the "moving past" operates, according to which memory is criminal when it is true to the truth, and the past does not exist, minus the way it is constructed at the moment. Reality quite often coincided with the predictions of seer authors. So "Translation activities in the Republic of Moldova, like all activities, were limited until 1991. ... The study of foreign languages and the functioning of the relevant areas (teaching, translation, etc.) were under constant control (...), because related to activities that could have a great ideological impact on individual groups or society as a whole (...). Due to censorship, Moldavian journalists had to write their articles in Russian at first, and only then the text was translated into "Moldavian". (16 15, p.24).

The fate of Alexander Robot (Alter Rotman, 1916 - 1941), a Romanian writer and avantgarde poet, journalist and literary critic, whose work was especially influenced by the encratic language, is also very indicative. In the work of A. Robot, whose poetry in the 30s was perceived by his contemporaries as extremely experimental and to which such outstanding figures of literature and culture as G. Calinescu, E. Lovinescu, Perpessicius and others, there is a creative degradation associated with severe historical conditions of 
r.\%\%

the Soviet regime, where he finds himself, seeing no other salvation from fascism. His brilliant work of the early 30s. The twentieth century, under the conditions of the literary dominant - socialist realism, underwent cardinal changes that marked the victory of ideological pressure over the fate of the artist. Enormous talent has been brought to a common and anonymous denominator. For comparison, here are two lines from famous poems: a). A flower is like a butterfly. / And I found myself, like in a seine, in the net of the day (Landscape, 1932); b). Here is the first Soviet collective farm spring. / And, crossing the steppe, the Dniester blooms (Blossoming Moldova, 1940) (16).

To translate, as noted by M. Leclerc-Olive, means an attempt to "avoid the imposed normativity" of concepts, i.e. create, feel, feel the need for a certain local re"conceptualization" All transhumanist trends pursue a single goal - the creation of a person devoid of physical disabilities. But practically none of the founders of these philosophical concepts raises the question of the place of emotions, morality, culture in the consciousness of the future person.

The fact is that they are simply not there: the posthuman is represented by the highest biotechnological species. Artificial intelligence will become the basis of his consciousness. Thus, general human concepts about good and evil, about human history, about relationships with his own kind will not have any meaning for the man-machine. He will lose a huge part of the all-round previous experience unnecessary for him.

It should be noted that "creative imagination often acts as temporarily fulfilling the duties of logical thinking. ... In the strict sense, logical thinking is possible when there is enough information or it can be obtained in a logical way. And if they are few and impossible to obtain, creative intuition and imagination help by creating missing links and linking facts into the system " $(6$, p. 106) until real facts and connections between them are found, confirming or refuting the work of the imagination. "This role of creative imagination is not the same in various fields of activity: for example, its role in scientific research is somewhat less than in literary creativity" $(6$, p. 106).

The process of literary translation, based on the recreational imagination of the translator, is a vivid embodiment of creativity. "A person has never come down to a character that could be covered with an acceptable simplification as a whole. This is the vain dream of many. As soon as he was understood in its simplest aspect, how a person is affirmed again in his usual complexity "(17, p. 596).

It is strange to expect from a machine artificial intelligence that it will think like a person or will be guided by the same morality as homo sapiens.

If we return to the thesis of $\mathrm{B}$. Ghiu and assume that all of us (including ordinary citizens) are constantly engaged in nothing more than translation, i.e. this property is inherent in all people, it is natural that in the process of communication (we are social creatures) in the minds of everyone, to one degree or another, the same processes occur as the author of an idea or a professional translator who transforms their thoughts into linguistic semantic forms. That is, when we say that the translation process at its internal stage is a very complex psychophysical system, completely different for each homo sapiens, with many parameters common, we also mean that this is one of the most powerful properties of its survival. In 
connection with the division of labor, the emergence of professional languages and the complexity of the social hierarchy, an encratic language, which has much in common with the practical manifestations of transhumanism in its aspirations for Artificial Intelligence, has acquired special significance in enhancing the impact on mass consciousness.

The bulk of the idea is not for transhumanism, because with all the desire it is impossible to create such an Artificial Intelligence that would include all the natural and unpredictable intellectual identity of mankind. Therefore, Perfect Artificial Intelligence can unify only certain stages of the transfer of the thought process into a visible and auditory form for the technical improvement of a cybernetic device with the human organic system (or what remains of it).

Technical thinking as an applied part of unpredictable volumetric thinking inherent in a certain high-tech caste of professionals has a tendency to streamline, systematize and regulate. The same applies to the scientific and technical spheres of the language that do not tolerate synonymization, i.e. variety. The incapacity for multidimensional perception of reality inevitably turns into the indifference of technocrats, and such indifference is a demonstration of the absence of humanitarian tools of difference.

The bearers of a technocratic language - an applied language that does not contain emotional, psychological, ethnic, ethical, etc. content, most often are the support of power, interested in the mechanistic curb of consciousness and the approach of an ordinary person to the machine by accustoming the latter to the idea of the benefits of its improvement with the help of technologies that allow to overtake natural thinking and other abilities. Most often, examples are given of the ability of modern computers to beat a person in chess or in the Chinese game GO with countless combinations. Hence the attempts to reduce everything (from socioeconomic interests) to a universal language of numbers, which does not contain emotional, moral and cultural and historical components. But human existence is not limited to games, no matter how complex they may be. They are, first of all, regulated games. One way or another, the solution to game problems can be calculated with the help of AlphaGo, programmed by a human.

Mark O'Connell emphasizes that transhumanists, no matter how rational they think they are, cannot inspire confidence or sympathy with their humanitarian limitations, and living in their future is very problematic, since they do not have a concept of life in its usual sense.

However, O'Connell feels this future in modern reality, because not always sure if he lives in the present.

Working with a computer, we noted the manifestation of a certain dependence on it in everyday intellectual work. And this concerns translation, above all. Modern machine translation is unsuitable for transporting figurative text to another language environment. However, there is an easy opportunity to transform figurative text into its opposite. You can verify this by resorting to the GOOGLE translator. There are real prerequisites for a satisfactory translation of technical, scientific, professional texts, that is, those for which polysemy is contraindicated. The higher the terminological and structural accuracy (with the absence of figurative and emotional features), which also has an international character, the higher the quality of the machine translation, because it does not 


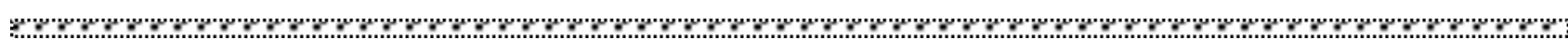

require from the machine what it cannot do to be human in every sense of the word.

So, when urgently translating our own text into another language, resorting to the help of a computer, quite deliberately (in which we gave a report in the subsequent introspective observation of our own translation process), we tried to formulate our thought lexically, grammatically and stylistically as neutral as possible adjusting to the algorithm of the machine. That is, we deliberately went "towards the machine", depriving ourselves of the possibility of figurative transmission of a message in order to facilitate our work.

When it comes to translating an unambiguous thought-text, such an approach to translating its meaning both in the source and in the target language is necessary, but if we are talking about a message that has precedent and other figurative aspects, then following the efficacy of the work, we lose in artistic expressiveness, and if we go further, then in the possibilities of creative self-expression and the development of the language as a whole.

Realizing that the whole complex of recognition and decoding of human communicative ability is inaccessible to the machine, now, without thinking about the consequences, being guided by pragmatics and going towards artificial intelligence, the computer user automatically goes to personal rapprochement with the machine and the irreplaceable loss of the natural course of translation of the thought-text, to its simplification of their own intellectual capabilities.

The process will go further due to the initially inherent tendency of a person to make his life easier, guided by socio-economic goals and pushing aside the emotional and ethical nuances. By reducing the amount of creative thought, the user follows the lead of its linear reproduction according to the imposed patterns of machine thinking. This is how the user's "education" is gradually imposed and carried out. So, it's not the victory of Artificial Intelligence, but the defeat of the human in pursuit of the illusion of its own improvement. For, by reducing our more time-consuming, but immeasurably wider creative opportunities for the sake of actualizing immediate tasks, we contribute to the loss of many skills and abilities.

Perversions in consciousness arise from satiety. One of the most ancient and most dangerous is the desire to create technologies for controlling human consciousness in the name of a very banal desire - unlimited power over their own kind, in the name of a pyramidal hierarchy with the so-called "superintelligence" at its top. While extolling science, current transhumanists primarily extol its applied results, ignoring fundamental sciences.

All that the encratic social system expects from us is the reduction of linguistic communication to the language of formulas and numbers. Freeing ourselves from the associative series, the precedence of thinking, etc., we lose huge layers of human experience, the empirical part of ourselves, and as a result, there remains the encratic language and the rudiments of a truncated biological nature that responds to electronic signals. It is becoming more and more obvious that it is easier to track individual mental activity using a machine than to create a Perfect Artificial Intelligence.

The history of transhumanism testifies to its mechanistic view of human life, namely that a person is a device, his duty is to become the best versions of himself, that is, transhumanism is a liberation movement that 
matter: an equivalent opposite interpretation, according to which such an apparent liberation is nothing more than a final and

\section{CONCLUSIONS}

A technical or specialized text differs from an artistic one by its one-dimensionality of meaning. Translation of such a text is available to Artificial Intelligence.

When translating artistic text, there is a significant difference between the mental operations of the translator and Artificial Intelligence. The process of translating creative thought into a speech form is due to numerous factors, namely: figurative and associative elements, psychosocial components, biological, genetic, emotional and historical memory, as well as culture and experience. The whole complex of recognition and decoding of human communication skills is inaccessible to a machine, that is, to Artificial Intelligence.

From our point of view, literary translation is an interdisciplinary activity. The science of it, as a study on the transformation of the figurative-emotional reflection of the world into a linguistic form, should become an independent part of the general theory of translation.

\section{ACKNOWLEDGEMENTS AND DISCLOSURES}

The author state that there is no declared conflicts of interest regarding this paper.

\section{REFERENCES}

1. Mark O'Connell. Artificial intelligence and the future of humanity. Moscow: Eksmo, 2019.

2. A.I. Korsakov. Religion and Science in the Works of the Founder of the First Positivism. In: Bulletin of PSTGU.

Series I: Theology. Philosophy. Issue 2 (40).Moscow, 2012.

3. Kai-Fu Lee. AI Superpowers. China, Silicon valley, and the new worlds order. Houghton Mifflin Harcourt.- Boston, New York, 2018.

4. www.cost.eu/cost-action/language-in-the-human-machine-era/

5. V.N. Komissarov Translation as an object of linguistic research. In: Problems of translation interpretation of the text in the works of Russian linguists of the late 20th, early 21st centuries. Yerevan: Lingua, 2009.

6. Yu. Golovin. Practical Psychologist Dictionary.2nd ed., Rev. and add. Minsk: Harvest, Moscow: AST, 2001.

7. Bogdan Ghiu. Europa este traducere. Interviu consemnat de Matei Martin. Dilema veche. 2015, nr. 586, p. 7-13.

8. V.D. Psurtsev. On the problem of translation and interpretation of a literary text: on one criterion of adequacy. In:

Problems of translation interpretation of the text in the works of Russian linguists of the late 20th, early $21 \mathrm{st}$

centuries.Yerevan: Lingua.

9. Philip Zimbardo, Michael Leippe. Social impact. - SPb. Ed. "Peter", 2000.

10. Le Conferenze dell'Associazione Culturale Italiana, 1973 B: Roland Barthes. Le bruissement de la langue P Seuil, 1984.

11. http://yanko.lib.ru/books/cultur/bart-all.htm

12. Katharina Reiss. Classification of texts and methods of translation. In: Questions of the theory of translation in foreign linguistics. Moscow, 1978.

13. Roland Barthes. Selected works. Semiotics. Poetics. Moscow: Progress, 1989.

14. George Orwell "1984”, pdf, 393 p. Free eBooks at Planet eBook.com 
120/Bulletin of Integrative Psychiatry ONew Series OSeptember 2021 O Year XXVII ONo. 3(90)

(1)

15. Irina Condrea. Traducerea din perspectivă semiotică. Chişinău: Cartdidact, 2006.

16. Alexandru Robot. Scrieri. Poezie. Proză. Publicistică. Eseu. Chișinău: Știința, 2018.

17. Fernand Braudel. Structures of everyday life: the possible and the impossible. T.I, Moscow Progress, 1986.

\section{Correspondence \\ Miroslava Metleaeva (Luchianchicova),}

PhD Philology, Researcher Institute of Romanian Philology "Bogdan PetriceicuHasdeu", Chișinău, Republic of Moldova, metleaevaslava@mail.ru

Submission: 14 may 2021

Acceptance: 22 aug 2021 